\title{
RELAÇÕES ENTRE ENSINAR CIÊNCIAS E A ESCRITA: REFLEXÕES SOBRE AS "ORIGENS" DE SEU PESQUISAR NO BRASIL
}

\author{
Daniela TOMIO \\ Universidade Regional de Blumenau (FURB), \\ Blumenau, Santa Catarina, Brasil
}

\begin{abstract}
Resumo: Esta pesquisa tem como objetivo caracterizar compreensões de pesquisadores brasileiros de Educação Científica que foram mediadoras do desenvolvimento de conhecimentos científicos sobre as relações entre o ensino de Ciências e a escrita. Para isso, socializa-se um recorte de uma investigação de estado da arte, em que se realizou uma análise histórico-epistemológica das pesquisas sobre escrita, divulgadas em periódicos e eventos científicos da área de Ensino de Ciências, considerando os aportes teóricos da epistemologia de Ludwik Fleck e uma compreensão de linguagem da Análise de Discurso francesa. As interpretações permitem compreender quando se iniciaram as publicações, as tendências da produção científica ao longo de sua história e a circulação de ideias entre os pesquisadores de Educação Científica com de outras áreas a fim de responder aos seus problemas de pesquisa.

Palavras-chave: Ensino de Ciências. Escrita. Pesquisa. Circulação de ideias.
\end{abstract}

INTRODUÇÃO

Mas sobre todas as invenções estupendas, que eminência de mente foi aquela de quem imaginou encontrar modo de comunicar seus próprios pensamentos mais recôndidos a qualquer outra pessoa, mesmo que distante por enorme intervalo de lugar e de tempo? Falar com aqueles que estão na 
Índia, falar com aqueles que ainda não nasceram e só nascerão dentro de mil ou 10 mil anos? E com que facilidade? Com as várias junções de vinte pequenos caracteres num pedaço de papel seja este o segredo de todas as admiráveis invenções humanas (GALILEU GALILEI, 2004).

Enquanto Galileu Galilei, nos idos do século XVI, admirava-se com a palavra escrita, e o seu poder em transcender as dimensões do tempo e espaço, possivelmente não imaginava que ela se tornaria não apenas um meio de circulação das ideias científicas, mas também seria o próprio objeto de estudo para futuras investigações de outros pesquisadores, especialmente da área de Educação em Ciências.

Essa afirmação tem, como primeira noção, as pesquisas de estado da arte organizadas por pesquisadores do cenário internacional, uma vez que foi lá que se iniciou o mapeamento e a discussão da produção científica sobre as relações entre o ensino de ciências e a escrita. Entre elas, o Canadense Rivard (1994) fez uma revisão da literatura acadêmica com enfoque específico na escrita para aprender ciências. Suas considerações finais, relativas à produção sobre a escrita até o ano de 1994, alertavam naquele contexto sócio-histórico que as pesquisas não estavam dando atenção devida às relações entre "escrever para aprender e mudanças conceituais" e "escrever para aprender e pensamento crítico".

Yore, Bisanz e Hand (2003) examinaram os vinte e cinco anos de publicação (1978-2003) sobre pesquisas com foco em linguagem no International Journal of Science Education e, ao apresentarem as atuais tendências das pesquisas sobre escrita para aprender ciências, discutem que a concepção de linguagem tem mudado, de uma perspectiva tradicional, como "veículo de transmissão do pensamento", para uma perspectiva funcionalista, em que a linguagem tem papel "constitutivo na negociação, elaboração e organização das ideias". Nesse sentido, a linguagem passa a ser caracterizada considerando o contexto dos grupos sociais que aprendem ciências.

Essas conclusões também são destacadas no estudo de Carlsen (2007). Ao fazer uma análise das publicações no sistema ERIC (Education Resources Information Center), de pesquisas sobre linguagem e aprendizagem de Ciências (1975 a 2002), organizando essas informações no Handbook of Research on Science Education, o autor concluiu que no período de 1975 a 1984, há um início e extensão de pesquisas com os termos chave educação em ciências e linguagem associado ao termo "formação de conceitos". No período de 1985 a 1994, há uma estabilidade na ocorrência dessas pesquisas. E, no período de 1995 a 2002, as pesquisas passam a tratar as questões de linguagem na educação científica mais associada ao termo chave "cultura". 
Em comum, esses autores concluíram que houve mudanças no estudo da linguagem, nos papéis considerados para a linguagem na educação científica e nas abordagens das pesquisas usadas para investigar a linguagem escrita na ciência e no ensino e aprendizagem de ciências ao longo dessas décadas. Os resultados de estudos sobre a cognição e aprendizagem humana, do emprego das novas tecnologias de informação e comunicação, da natureza da ciência e da tecnologia e as suas implicações na nossa cultura são alguns dos exemplos de novos conhecimentos que contribuíram para o surgimento de condições sócio-históricas que permitiram e instauraram a necessidade de se repensar as pesquisas sobre as conexões entre aprender e ensinar ciências e a linguagem. Ainda, acabaram por influenciar a educação científica e tecnológica nas discussões e nas reformas curriculares, na formação de professores e nas práticas de sala de aula (CARLSEN, 2007; RIVARD, 1994; YORE; BISANZ; HAND, 2003).

E no contexto da produção acadêmica brasileira, como se configura a investigação sobre essas relações entre ensinar, aprender e escrita em aulas de ciências? Um inventário mais amplo ${ }^{1}$ em que realizamos das pesquisas, cujo objeto de estudo foi a "linguagem escrita" e que foram socializadas por pesquisadores, em eventos e periódicos nacionais, de Educação Científica, entre os anos de 1995 a 2010, permite-nos localizar a origem das pesquisas no Brasil e inferir que essa produção também se intensificou nos últimos anos no país.

No referido estudo interessou-nos caracterizar as condições dessa produção: Quem investiga? Quais são os problemas investigados? Onde investigam? Com quais sujeitos investigam? Quais referenciais teóricos as inspiram? Como investigam? E quais sentidos atribuem ao papel da linguagem escrita e as suas relações com aprender ciências? A partir dessas interrogações buscamos organizar um panorama da investigação científica sobre a linguagem escrita na área de Educação em Ciências, compreendida entre os anos 1995 a 2010. Neste artigo, divulgamos uma das dimensões analisadas, com destaque para a constituição do campo de pesquisa sobre escrita no ensino de Ciências a partir de uma análise histórico-epistemológica dessa produção.

Assim, aqui objetivamos caracterizar compreensões de pesquisadores brasileiros de Educação Científica que foram mediadoras do desenvolvimento de conhecimentos científicos sobre as relações entre a escrita e o ensino de Ciências.

Para isso, dialogamos com alguns dos aportes teóricos propostos pelo epistemólogo polonês Ludwik Fleck (1986a), que afirma: 
[...] querendo ou não, não podemos nos livrar de um passado que - com todos os seus erros - segue vivo em conceitos herdados, nas formas de conceber os problemas, nos programas de ensino formal, na vida diária, na linguagem e nas instituições. Não existe nenhuma geração espontânea dos conceitos, eles são, por assim dizer, - determinados por seus antepassados. O passado é muito mais perigoso - ou, melhor dito, só é perigoso - quando nossos vínculos com ele se mantêm inconscientes e desconhecidos (FLECK, 1986a, p. 67, grifo do autor).

Nesse sentido, pressupomos que para explicitar a produção científica contemporânea sobre a linguagem escrita, situando-a na área de investigação Educação em Ciências, torna-se necessário compreendermos, no desenvolvimento histórico da sua elaboração, as condições de produção que permitiram aos coletivos de pesquisadores instaurarem os problemas de pesquisa e produzirem sentidos sobre esse objeto de estudo. Ainda, quando nos situamos hoje, pesquisando sobre a escrita, entendemos que estamos contribuindo para escrever essa história e, portanto, temos ligação e responsabilidades para com esse passado, daí uma justificativa para discutirmos esse panorama.

Além do aporte de uma compreensão epistemológica, a concepção de linguagem que orienta este estudo é fundada na Análise de Discurso da linha francesa, em seus desdobramentos no Brasil a partir dos estudos de Orlandi $(2008,2009)^{2}$. Nesta se reconhece que os sujeitos produzem discursos em determinadas situações comunicativas, marcados pelas suas condições de existência. Desse modo, os sentidos não estão fixados, a priori, como essências das palavras, nem tampouco podem ser qualquer um; há uma determinação sócio-histórica que media a interpretação que o sujeito faz da realidade com a qual ele está relacionado.

\section{Percurso investigativo}

Apresentamos, como já destacado, uma das dimensões interpretadas em uma pesquisa de estado da arte sobre relações entre o escrever e o ensino de Ciências. Para situar a procedência dos dados citados, descrevemos sucintamente as fontes e o método que foram investigadas:

a) periódicos científicos nacionais da área de Ensino de Ciências: Foram observadas todas as edições disponíveis na internet dos periódicos da área de Ensino de Ciências, da sua primeira edição on-line até o ano de 2010, compreendendo assim um período de análise entre os anos de 1996 a 2010. 
Foram investigados os periódicos nacionais: Investigações no Ensino de Ciências (UFRGS); Experiências no Ensino de Ciências (UFRGS); Ensaio: Pesquisa em Educação em Ciências (UFMG); Ciência e Ensino (UNICAMP); Ciência \& Educação (UNESP); Alexandria (UFSC); Revista Brasileira de Pesquisa em Educação em Ciências (Belo Horizonte); Revista Brasileira de Ensino de Física (Porto Alegre); Revista Brasileira de Ensino de Química (Campinas); Revista de Ensino de Biologia (SBEnBIO) e Química Nova: Divulgação da Sociedade Brasileira de Química. Foram identificados 17 artigos cientíicos dos periódicos analisados, com divulgação de pesquisas, cujo objeto de estudo era a "escrita".

b) atas dos Encontros Nacionais de Pesquisa em Educação em Ciências (ENPECs): foram observadas as suas sete edições, entre os anos de 1997 a 2010. Os artigos selecionados somaram 44 ocorrências.

No inventário foram identificados 61 artigos de pesquisas, no entanto, quatro deles foram apresentados novamente em uma edição do ENPEC e em um periódico científico, assim o corpus de análise ficou constituído de 57 artigos.

Os artigos foram selecionados com critérios predefinidos e elaborados paralelamente aos contatos iniciais com a produção. Assim, foram investigados todos os trabalhos comunicados nas fontes, tomando-se por base uma leitura exploratória dos títulos, palavras-chave e resumos para a seleção de pesquisas que obedecessem a algum dos critérios: que tivessem como palavras-chave: escrita, escrever, escrevendo, redação; que investigassem a elaboração escrita de um gênero textual no ensino de ciências na escola ou universidade (diário, portfólio, jornal, weblog, relatórios, dentre outros); que abordassem o estudo de alfabetização científica, letramento, linguagem, discurso, argumentação ou comunicação com referência e ênfase à escrita em suas discussões; que tivessem como foco a formação de autores ou de autoria com a escrita como objeto de estudo.

É importante destacar que consideramos como ensino de ciências as áreas de conhecimento científico veiculadas nas fontes analisadas (Biologia, Física, Química, Biofísica, Bioquímica, Geociências e Educação Ambiental).

Para a elaboração do corpus de análise da pesquisa, procedemos à leitura de cada texto selecionado e reunimos as informações de acordo com um roteiro, elaborado com as seguintes unidades de análise: problema de pesquisa, objetivos, justificativa, classificação da pesquisa, instrumentos de coleta de dados e métodos de análise, grupo investigado, gênero discursivo de escrita investigado, intenção comunicativa, autores citados e conclusões. Neste artigo, em que socializamos uma das dimensões do estado da arte, 
os dados analisados se referem "aos autores citados" nas pesquisas. Esses foram organizados em duas categorias de análise: circulação intracoletiva (autores específicos da área de ensino de Ciências e que investigam linguagem e linguagem escrita) e circulação intercoletiva (autores de outras áreas de conhecimento).

Cabe também notar que na perspectiva da Análise do Discurso, a escolha de um corpus teórico-metodológico precisa ser remetida à formação discursiva a que pertence o pesquisador. É nela que o sujeito se inscreve socialmente e, como destaca Orlandi (2009), que vai condicionar a partir do conjunto de convenções, normas e acordos sobre o que dizer/ escrever ou silenciar, bem como legitimar a sua identificação em um grupo. Da mesma forma, Fleck (1986b, p. 49) vai afirmar que:

Cada conhecedor tem seu próprio estilo conforme sua tradição e educação. Dentro de uma quase infinita diversidade de possibilidades, cada maneira de conhecer seleciona diferentes questões, as relaciona de acordo com diferentes regras e a diferentes propósitos. Membros de diferentes comunidades científicas vivem em suas próprias realidades científicas e profissionais.

Em outras palavras, o estilo de pensamento abrange tanto os pressupostos, a partir dos quais um coletivo constrói conhecimentos, quanto os métodos empregados nas pesquisas. Ele é marcado por características comuns dos problemas e das formas de investigar que interessam a uma coletividade e, com isso, possibilita e define uma maneira de pensar e agir de um coletivo de cientistas em um determinado contexto e momento da história.

Desse modo, compreendemos que a nossa inserção, bem como dos outros pesquisadores - autores dos artigos examinados neste estudo - em um estilo de pensamento, acaba por determinar as nossas ideias e práticas na produção e circulação de conhecimentos científicos, o que implica a aceitação de "uma" análise dentre outras, e que produzir ciência é uma atividade isenta de neutralidade.

DeSENVOLVIMENTO DAS PESQUISAS SOBRE A ESCRITA NO ENSINO DE CIÊNCIAS NO BRASIL

Para analisar as condições de produção das pesquisas é preciso entendê-las, no sentido mais estrito, no contexto imediato da sua formulação e, ao mesmo tempo, considerá-las em um sentido mais amplo, no contexto 
sócio-histórico e sob quais forças sociocognitivas se dá essa produção e a circulação do conhecimento sobre a escrita no ensino de Ciências.

Nas palavras de Fleck (1986a, p. 85), “O já conhecido condiciona a forma e a maneira do novo conhecimento, e este conhecer expande, renova e dá sentido novo ao conhecer". Com elas, queremos destacar a relevância de se identificar e caracterizar tendências da produção científica em uma área ao longo de sua história e, ao mesmo tempo, localizar, no atual "estado do conhecimento", contribuições e novas possibilidades para pesquisa.

Em nosso inventário identificamos que as pesquisas na área de Ensino de Ciências sobre linguagem, com atenção à escrita, começaram a ser divulgadas nos periódicos científicos e nos ENPECs a partir de 1997 (1a edição), sendo que as duas pesquisas divulgadas nesse Encontro foram os únicos estudos publicados, novamente, no ano de 1998, em periódicos.

Os trabalhos de Mortimer, Chagas e Alvarenga $(1997,1998)$ - "Linguagem científica versus Linguagem comum nas respostas escritas dos vestibulandos" - e de Lima e Carvalho $(1997,1998)$-"Analisando o conhecimento físico através da linguagem" - inauguraram, nestes veículos, a circulação de conhecimento científico sobre a linguagem escrita no Brasil.

Quando comparamos essa informação com os focos temáticos de pesquisa na área de Educação em Ciências podemos inferir que a investigação sobre linguagem e as relações entre escrever e aprender ciências são recentes no nosso país. Como apoio a esse pressuposto, citamos o estudo de Megid Neto (2001). O autor realizou um estado da arte sobre o ensino de Ciências no nível fundamental, descrevendo e analisando as características e as tendências da pesquisa acadêmica brasileira, no período de 1972 a 1995.

Megid Neto (2001) identificou na análise de teses e dissertações focos temáticos privilegiados para pesquisa. Nesses, não há nenhuma ocorrência de estudos no ensino de Ciências relacionados especificamente à linguagem, até o ano de 1995. Ao contrário disso, no contexto internacional, Rivard, já no ano de 1994, publicava no Journal of Researh In Science Teaching, uma revisão de trabalhos sobre a escrita para aprender ciência e suas implicações para o ensino e a pesquisa. Em seu estudo, ele localizou mudanças nas ideias e nas práticas de pesquisadores, principalmente norte-americanos, ao longo do tempo e, dentre as suas conclusões, afirmou que para uma nova agenda de pesquisa e para a formação de professores seria preciso considerar uma nova compreensão da escrita para aprender ciências, substituindo o modelo de ensino que enfatiza a transmissão dos conteúdos para um modelo que aborde a exploração e a interpretação pelos alunos. 
Rivard (1994) apontava a necessidade de investigações sobre a escrita, partindo de outra epistemologia de aprendizagem para o ensino de Ciências e, com isso, um modo de conceber a linguagem em seu papel constitutivo na aprendizagem e formação do sujeito e não apenas como um instrumento de comunicação do conhecimento.

No Brasil, também, esse estado do conhecimento parece ter contribuído para a origem das pesquisas sobre linguagem. Elaboramos esse pressuposto com base em uma leitura que realizamos para os referenciais teóricos empregados pelos autores brasileiros das pesquisas analisadas. Constatamos que, com exceção de dez trabalhos, 47 artigos de pesquisa referenciam os fundamentos de Vigotski (de várias obras e edições). Ainda, quando não explicitam o autor, empregam uma linguagem estilizada em seus textos que tem as marcas dessa perspectiva teórica, como por exemplo: psicologia sócio-histórica, psicologia sociocultural, interacionismo, teoria sociocultural e caráter ou cunho sócio-histórico. Essa observação tem conformidade com o que afirmam Machado e Moura (1995, p. 27):

A partir da década de 90 é possível se perceber um movimento de pesquisadores na área de ensino de ciências no sentido de incorporar em suas análises e em seus programas de pesquisa pressupostos que parecem oferecer uma nova perspectiva para o estudo da elaboração de conceitos científicos no âmbito da sala de aula. [...] Esses trabalhos vêm sendo realizados a partir dos pressupostos teórico-metodológicos da perspectiva sócio-histórica.

Frente a isso nos perguntamos: o que mobilizou os pesquisadores brasileiros de Ensino de Ciências a problematizarem as relações entre ensinar, aprender, linguagem e escrita, buscando as contribuições de perspectivas teóricas relacionadas à corrente sócio-histórica ou sociocultural?

Mortimer (1996), fazendo um resgate histórico sobre as pesquisas no ensino de ciências, informa que a partir da década de 70 apareceram vários estudos preocupados em responder quais são os conteúdos das ideias dos estudantes em relação aos diversos conceitos científicos aprendidos na escola? Assim, por mais de 20 anos o estudo das concepções alternativas dos estudantes, com o construtivismo como base, foi o sistema de ideias que determinou várias das formas de conceber os problemas e de subsidiar pesquisadores.

A tendência à persistência de um sistema de ideias nos demonstra que essa é marcada por um estilo e que as características desse é que determinam e condicionam cada uma das funções da produção de conhecimento, como destaca Fleck (1986a, p. 85, grifo nosso): 
O caráter fechado dos sistemas, assim como as interações entre o conhecido, o que se está por conhecer e o cognoscente garantem a harmonia dentro do sistema. Porém, ao mesmo tempo, também asseguram a harmonia das ilusões, que, precisamente por isto, não podem desmascarar-se nunca desde dentro do estilo de pensamento.

No entanto, ao considerarmos o desenvolvimento do conhecimento científico em ensino de Ciências no Brasil, podemos notar em determinado momento que ocorre uma mudança nos objetos de estudo, bem como em seus modos de investigação. A comunidade científica passa a questionar as pesquisas sobre levantamentos de concepções de estudantes; criticar aspectos filosóficos, psicológicos e pedagógicos do construtivismo e problematizar as investigações do entendimento individual dos estudantes sobre fenômenos científicos. Ampliam-se os interesses para compreender como se dão as interações entre estudantes e professores para aprender ciências (MORTIMER; SCOTT, 2002). Assim, surgem as complicações.

As complicações são explicadas por Fleck (1986a) como aquelas exceções que se fazem conscientes aos pesquisadores quando o estilo de pensamento do coletivo se revela limitado e não permite mais responder aos novos problemas nos atuais contextos sociais. Do confronto com as complicações é que pode ocorrer a instauração, a extensão e a transformação de um novo estilo de pensamento.

Nessa perspectiva, interpretamos que, a partir da década de 90 , coletivos de pesquisadores brasileiros de Educação Científica passaram a dialogar com outros coletivos (da Psicologia, Sociologia, Linguística) sobre perspectivas teóricas e metodológicas relacionadas à corrente sócio-histórica ou sociocultural, caracterizando o que Fleck (1986a) denomina de circulação intercoletiva de ideias. Pressupomos que a apropriação pelos pesquisadores de um novo corpo de conhecimentos e práticas para a investigação, com o intuito de melhor compreenderem como se davam os processos interativos no ensino e na aprendizagem de ciências, sinalizou uma nova direção para as pesquisas e para a instauração de um estilo de pensamento.

Nessa tradição, o processo de conceitualização é equacionado com a construção de significados (Vygotsky, 1987), o que significa que o foco é no processo de significação. Os significados são vistos como polissêmicos e polifônicos, criados na interação social e então internalizados pelos indivíduos. Além disso, o processo de aprendizagem não é visto como a substituição das velhas concepções, que o indivíduo já possui antes do processo de ensino, 
pelos novos conceitos científicos, mas como a negociação de novos significados num espaço comunicativo no qual há o encontro entre diferentes perspectivas culturais, num processo de crescimento mútuo. As interações discursivas são consideradas como constituintes do processo de construção de significados (MORTIMER; SCOTT, 2002, p. 2).

A incorporação dos estudos sobre as interações sociais nos programas e grupos de pesquisa de Educação Científica acabaram por fomentar novas formas de conceber e investigar problemas relacionados ao ensino eà aprendizagem de ciências à luz de um estilo de pensamento que considera a linguagem como constitutiva desses processos. Parece-nos que isso cooperou para o crescente desenvolvimento do interesse e do intercâmbio de pesquisadores em responder ao questionamento: como a atividade cognitiva - ou o pensamento, ou a produção de sentidos - dos sujeitos se estabelece por meio das relações com o "outro" e o contexto, mediadas pela linguagem?

Assim, pressupomos que em busca de respostas para os desdobramentos desse problema se inicia um "coletivo de pensamento" (FLECK, 1986a) sobre a linguagem, dentre os outros coletivos de pesquisadores, na área de ensino de Ciências.

\section{A CIRCULAÇÃO INTRA E INTERCOLETIVA DE IDEIAS}

Uma forma para problematizar como um coletivo de pensamento de pesquisadores de ensino de ciências interage entre si e com outros com o objetivo de responder aos seus problemas de investigação é recorrer às suas referências para identificar aqueles autores que são empregados como bases teóricas e metodológicas. Nas palavras de Fleck (1986a), implica caracterizar como ocorre a circulação intercoletiva e intracoletiva de ideias $^{3}$ entre o círculo esotérico, ou seja, entre os membros de coletivos de especialistas/ pesquisadores de determinadas área de conhecimento que compartilham de estilos de pensamento no enfrentamento de seus problemas de pesquisas.

Como já discutimos anteriormente, a interlocução de coletivos de pesquisadores de ensino de ciências com outros coletivos de perspectivas teóricas socioculturais ou sócio-históricas em virtude de problemas de pesquisas relacionados à linguagem acabaram por contribuir para a instauração de um novo estilo de pensamento. Como faz notar Fleck (1986a, p. 156-7), “Esta mudança de estilo de pensamento - quer dizer, esta mudança na disposição 
para o perceber orientado - oferece novas possibilidades de descobrimentos e cria fatos novos. Este é o significado epistemológico mais importante da circulação de pensamento intercoletiva".

Assim, em uma análise das produções sobre escrita no ensino de Ciências podemos evidenciar o papel da interação, na circulação intercoletiva, do círculo esotérico (de pesquisadores) de Educação em Ciências, principalmente com autores dos campos da Psicologia e Linguística/ Análise de Discurso como: Vigotski; Bronckart; Michel Pêcheux; Bakhtin e Eni Orlandi, uma vez que requerem a elaboração de novas compreensões e formas de enfrentamento dos problemas de pesquisa, próprias do campo da linguística, e relativamente novas no âmbito da Educação Científica.

É necessário destacar que a apropriação desses fundamentos não se dá pela simples soma à área de Educação Científica, mas sim pela sua transformação, pois, recordando Fleck (1986a, p. 158) "a comunicação não ocorre nunca sem transformação e sem que produza uma remodelação de acordo com o estilo". Da mesma forma, para $A D$, os sentidos não são apenas captados dos textos pelos sujeitos, mas sim são produzidos numa relação deles com os textos, mediada por um dispositivo teórico (ORLANDI, 2009).

Desse modo, pressupomos que os aportes acabaram por se transformar, pelos coletivos de pesquisadores do ensino de Ciências, em virtude das exigências sócio-históricas que determinam os objetivos para a educação científico-tecnológica e, por consequência, dos problemas de pesquisas específicos dessa área.

Além disso, podemos notar nas pesquisas analisadas uma crescente tendência dos pesquisadores de outros coletivos da Educação científica, como de alfabetização e letramento cientííco (BRANDI; GURGEL, 1999, 2002; SOARES; COUTINHO, 2007); formação de professores (FREITAS; PANIZ, 2005; GALIAZZI et al., 2005); elaboração do conhecimento físico por meio de experimentos (HINGEL; LIMA; XAVIER, 2005; LIMA; CARVALHO; GONÇALVES, 1998; PEREIRA; SOARES; ANDRADE, 2011); habilidades de argumentação (ASEM; TRIVELATO, 2009; OLIVEIRA; BATISTA; QUEIROZ, 2009; VALLE; MOTOKANE, 2009); dentre outros, em investigarem relações entre seus objetos de estudos e a linguagem escrita. Tal fato pode ser explicado pela proximidade das concepções e pelo diálogo entre os referenciais desses coletivos. Isso se aproxima do que Delizoicov (2004, p. 169) destaca em seu estudo sobre a pesquisa em Ensino de Ciências:"[...] há, então, a existência de distintos níveis de circulação intercoletiva de conhecimentos e práticas entre os vários grupos que constituem o campo de pesquisadores de EC". 
Já quando observamos as citações e referências de autores da área de Educação Científica que investigam a linguagem e, especificamente, a escrita, com a finalidade de caracterizar se já existe uma circulação intracoletiva de ideias e práticas desse círculo esotérico, podemos notar que:

- nos primeiros anos (1997-2000) da produção científica sobre escrita, os autores citados, que têm formação em ciências exatas e naturais, geralmente são estrangeiros, sendo que os mais referenciados são: Driver et al. (1999); Halliday e Martin (1993); Rivard (1994); Lemke (1990) e Scott (1998). Esses autores tratam de questões mais amplas da linguagem no ensino de ciências, alguns deles não sendo referências específicas sobre a linguagem escrita;

- a partir do ano 2000, os autores anteriormente citados continuam, com menor expressão, a ser citados pelos pesquisadores brasileiros e aparecem estudos que apresentam os levantamentos realizados sobre linguagem e linguagem escrita na ciência e no ensino de ciências dos autores estrangeiros Rivard (1994) e Yore, Bisanz e Hand (2003);

- o artigo de Mortimer e Scott (2002) é citado em grande parte das pesquisas sobre escrita como referência teórica, principalmente justificando a necessidade de estudos que tenham como objeto a linguagem e, por isso, muitos tomam esses autores como um marco neste campo de investigação no Brasil;

- depois do ano 2000 é possível localizar o predomínio de quatro referenciais teórico-metodológicos, já constituídos por autores brasileiros de Ensino de Ciências, utilizados pela maioria dos que investigam a linguagem escrita e as suas relações com ensinar e aprender ciências nos diferentes níveis de ensino. Esses referenciais aparecem, também, com funções distintas nas pesquisas, ora como base teórico-metodológica; ora só como referencial metodológico; ora só referencial teórico.

Quadro 1 - Referenciais teórico-metodológicos mais empregados nas pesquisas sobre escrita no Ensino de Ciências

\begin{tabular}{|c|c|c|}
\hline Referências & $\begin{array}{l}\text { Autores mais } \\
\text { referenciados }\end{array}$ & Ênfase \\
\hline \multirow{2}{*}{$\begin{array}{l}\text { A linguagem } \\
\text { [escrita] na } \\
\text { gênese das } \\
\text { explicações } \\
\text { causais }\end{array}$} & \multirow{2}{*}{$\begin{array}{l}\text { Carvalho (2011) } \\
\text { Oliveira, } \\
\text { Carvalho (2005) }\end{array}$} & $\begin{array}{l}\text { "Falar, ouvir e procurar uma explicação sobre os fenômenos, } \\
\text { depois escrever e desenhar, isto é, se expressar em } \\
\text { diversas linguagens, solidifica e sistematiza os conceitos } \\
\text { aprendidos". (CARVALHO, 2001, p. 184, grifo nosso) }\end{array}$ \\
\hline & & $\begin{array}{l}\text { "Escrever analiticamente requer uma posição lógica reflexiva } \\
\text { que estimula os estudantes a refinar seu pensamento, } \\
\text { aumentando, assim, seu entendimento do assunto } \\
\text { estudado"“. (OLIVEIRA, CARVALHO, 2005, p. 349). }\end{array}$ \\
\hline
\end{tabular}




\begin{tabular}{|c|c|c|}
\hline Referências & $\begin{array}{l}\text { Autores mais } \\
\text { referenciados }\end{array}$ & Ênfase \\
\hline $\begin{array}{l}\text { Ferramenta } \\
\text { sociocultural }\end{array}$ & $\begin{array}{l}\text { Mortimer e } \\
\text { Scott (2002) }\end{array}$ & $\begin{array}{l}\text { "[...] uma ferramenta para analisar a forma como os professores } \\
\text { podem agir para guiar as interações que resultam na } \\
\text { construção de significados em salas de aula de ciências. Essa } \\
\text { ferramenta é o produto de uma tentativa de desenvolver } \\
\text { uma linguagem para descrever o gênero de discurso de } \\
\text { salas de aula de ciências". (MORTIMER; SCOTT, 2002, p. 2) }\end{array}$ \\
\hline $\begin{array}{l}\text { Análise } \\
\text { Textual } \\
\text { Discursiva }\end{array}$ & $\begin{array}{l}\text { Moraes e } \\
\text { Galiazzi (2006) }\end{array}$ & $\begin{array}{l}\text { "[...] a análise textual discursiva como procedimento de pesquisa que } \\
\text { permite quatro reconstruções concomitantes: } 1 \text {. do entendimento } \\
\text { de ciências e de seus caminhos de produção; } 2 \text {. do objeto da } \\
\text { pesquisa e de sua compreensão; } 3 \text {. da competência de produção } \\
\text { escrita; } 4 \text {. do sujeito pesquisador. Argumenta-se que a análise } \\
\text { textual discursiva cria espaço de reconstrução, envolvendo-se nisto } \\
\text { diversificados elementos, especialmente a compreensão da produção } \\
\text { de significado sobre os fenômenos investigados e a transformação } \\
\text { do pesquisador. (MORAES; GALIAZZI, 2006, p. } 117 \text {, grifo nosso) }\end{array}$ \\
\hline $\begin{array}{l}\text { Análise de } \\
\text { Discurso }\end{array}$ & $\begin{array}{l}\text { Almeida (2004); } \\
\text { Almeida, Souza/ } \\
\text { Cassiani (2005); } \\
\text { Queiroz (2001) } \\
\text { e outros artigos } \\
\text { com orientação }\end{array}$ & $\begin{array}{l}\text { "[...] a linguagem não pode ser pensada como se fosse } \\
\text { transparente. Ou seja, a produção de sentidos entre interlocutores } \\
\text { não é idêntica. E, entre as noçôes de apoio, destacamos as } \\
\text { "condições de produção", fazendo-nos pensar na importância da } \\
\text { constante consideração tanto das condições imediatas quanto } \\
\text { das sócio-históricas na análise dos processos de produção } \\
\text { de sentidos." (ALMEIDA; CASSIANI; OLIVEIRA, 2008, p. 18) }\end{array}$ \\
\hline
\end{tabular}

Fonte: Tomio (2012, p.196).

Podemos observar nos quatro referenciais que há uma convergência no sentido de evidenciarem a linguagem como constitutiva dos processos de aprender do estudante. Igualmente, percebemos que, embora haja particularidades significativas entre esses referenciais que os diferenciam nas compreensões do papel da linguagem escrita no ensino e na aprendizagem da ciência, há uma tendência, que aparece no decorrer dos anos, desses autores, de seus orientandos ou daqueles que os empregam como referenciais em suas pesquisas, em compartilharem de conceitos da Análise de Discurso, em suas distintas filiações teóricas.

Essa influência pode ser observada até mesmo em pesquisas analisadas que não assumem os pressupostos teórico-metodológicos da Análise de Discurso, mas que passam a valorizar nos fenômenos discursivos investigados, também, os aspectos exteriores à enunciação dos sujeitos, como as condições de produção. Ainda, muitos autores empregam uma linguagem estilizada relacionada a esse aporte, como por exemplo: discurso, formação discursiva, produção de sentidos, gêneros discursivos, ou apenas citam os nomes de autores desses referenciais. Não obstante, em alguns casos, o emprego desses termos não revela marcas de transição nas concepções de linguagem, uma vez que nos procedimentos metodológicos de suas pesquisas não há coerência com o corpus analítico da Análise de Discurso, assemelhando-se mais aos procedimentos da análise de conteúdo. 
As duas abordagens dos dados em pesquisas sobre linguagem escrita são distintas. Enquanto na Análise do conteúdo se trabalha principalmente com os produtos da escrita do estudante para compreender o conteúdo contido no texto, na Análise de Discurso se reconhecem os textos escritos como instâncias discursivas atravessadas por um conjunto de determinantes e, portanto, interessa compreender as condições de produção que permeiam a escrita deles e como se constituem sujeitos-autores nesse processo de escrever ao aprenderem ciências na escola.

Também Pinhão e Martins (2009), ao realizarem um levantamento da produção científica no Brasil com foco para a Análise de Discurso e a pesquisa em ensino de Ciências, evidenciam que há um uso indiscriminado e problemático dos termos discurso e Análise de Discurso, distanciando-os, muitas vezes, dos princípios básicos que orientam o campo dos estudos discursivos. Ainda, notaram que a maioria dos autores não explicita o desenho metodológico de suas pesquisas, restringindo apenas à nomeação das categorias de $A D a$ serem empregadas. Concordamos com as autoras que

[...] o uso da Análise de Discurso, quando pautado apenas na aplicação de categorias analíticas, fora de considerações de natureza sócio-histórica, equivoca-se e esvazia a teoria. Em consequência pouco colabora para a consolidação de um corpo teórico metodológico para o campo de pesquisa em ensino de Ciências (PINHÃO, MARTINS, 2009, p. 6).

Assim, a pluralidade de sentidos sobre a AD nas pesquisas, ou mesmo as razões para buscarem essa filiação teórica, merecem a nosso ver atenção em uma agenda de pesquisa na Educação em Ciências. Nosso atual pressuposto para a atual ênfase de fundamentos teórico-metodológicos da AD nas pesquisas se deve, entre outros, a dois motivos complementares:

1) Com a circulação intercoletiva de conhecimentos, há um deslocamento, nas pesquisas de Educação em Ciências, da ênfase em problematizar os processos individuais para investigar os processos discursivos coletivos na construção de conhecimento científico e as suas relações com a exterioridade (MACHADO; MOURA, 1995; MORTIMER; SCOTT, 2002);

2) A circulação intracoletiva do conhecimento elaborado pelos coletivos de pensamento da Educação Científica em periódicos e eventos favorece a extensão de formas de conceber e investigar problemas de pesquisas. Podemos observar no exame da produção científica que autores mais recentes foram orientandos, em seus trabalhos de pós-graduação, dos primeiros autores de Educação científica (físicos, químicos, biólogos) que iniciaram a 
circulação de fundamentos da AD e acabaram por formar coletivos e linhas de pesquisas em diferentes programas de pós-graduação, intensificando a extensão dessas ideias e práticas.

Sobre essa atitude na pesquisa, Fleck (1986a, p. 153) afirma que "A estrutura geral do coletivo de pensamento leva que a comunicação intelectual intracoletiva produza por razões sociológicas - sem ter em conta o conteúdo e a legitimação lógica - o reforçamento das criações intelectuais". Desse modo, podemos pressupor que a circulação de sentidos entre os pesquisadores de Educação Científica que utilizam a AD como aporte legitima, além de suas concepções, a formação de um ver formativo, um perceber orientado para os objetos de estudo que lhes interessam, sinalizando o uso compartilhado de referenciais teórico-metodológicos para a investigação dos problemas de pesquisa.

Ainda, em relação ao emprego das citações pelo coletivo de pesquisadores:

Lembremos que faz parte do discurso científico a citação de outros textos, com seus autores, ou seja, é da ordem do discurso da ciência a explicitação da intertextualidade que sustenta suas formulações e o reconhecimento das diferentes funções-autor, que intervêm ao longo do texto, reconhecimento garantido pelas citações (ORLANDI, 2008, p.1).

Em síntese, identificar os referenciais e, por consequência, os autores citados nas pesquisas têm a vantagem de possibilitar o reconhecimento de conhecimentos que têm sido compartilhados entre os pesquisadores da Educação Científica, o que contribui para a sua extensão, assim como a sua problematização, considerando as questões emergentes de nossa época.

\section{CONSIDERAÇÕES FINAIS}

Em uma leitura diacrônica das pesquisas selecionadas neste estudo, não vislumbramos marcas teóricas e/ ou metodológicas que revelassem diferentes períodos ou períodos de transição nas formas de investigação de objetos de estudo relacionados à escrita no ensino de ciências. Pressupomos que tal fato seja em decorrência de a produção das pesquisas concentrar-se basicamente nos últimos dez anos e ter em comum uma discussão da linguagem associada a uma perspectiva epistemológica sócio-histórica ou sociocultural para a aprendizagem. 
Por outro lado, em uma análise sincrônica dessa produção científica podemos encontrar o que Fleck (1986a) denomina de matizes de estilo de pensamento, ou seja, para além do compartilhamento de objetivos para a educação científica e de pressupostos - epistemológicos e educacionais existem, em um mesmo estilo de pensamento, diferentes coletivos que privilegiam recortes teórico-metodológicos na forma de investigar os problemas de pesquisa, acabando por constituir distintos matizes.

$\mathrm{Na}$ análise dos artigos notamos que a maioria dos autores, na circulação intracoletiva de ideias, geralmente citam e compartilham as mesmas pesquisas sobre escrita, contudo, em conformidade com seu "matiz de estilo de pensamento", tecem críticas ou reforços, por exemplo, às compreensões veiculadas sobre o que seja linguagem (produto ou processo; a função de meio, instrumento ou estruturante) e, por consequência, sobre as funções do escrever.

Em nossa leitura, essas diferenças nos focos das pesquisas, embora gerem poucas afinidades teórico/ metodológicas entre os pesquisadores, ainda não comprometem, a ponto de tornar-se incompatível, a comunicação no coletivo de pensamento sobre linguagem em Educação Científica.

Essa análise da produção acadêmica com foco na origem de um campo de estudo no Ensino de Ciências se faz relevante, uma vez que concordamos com Macías e Maturano (2000) quando asseveram que as publicações são um meio de criar e recriar o que os coletivos de investigadores pensam e, com isso, podem contribuir para aqueles que buscam na leitura cotejar as ideias dos autores com as suas próprias, enriquecerem-se com eles e encontrar novos enfoques de pesquisa.

Supomos que uma análise histórica-epistemológica, tendo em vista o que foi apresentado, poderá contribuir para o/s coletivo/s de pesquisadores na reflexão de aspectos que vêm sendo priorizados nos programas de pós-graduação para a "extensão" de um estilo de pensamento sobre a linguagem e a linguagem escrita.

Além do círculo esotérico de pesquisadores esta análise também pode ser de utilidade para professores e formadores de professores, que desejam conhecer acerca da investigação em ensino de ciências e suas interfaces com a linguagem, suas tendências e conhecimentos. Da sua interlocução com os pesquisadores pode-se ampliar o debate dos resultados das pesquisas e as suas relações com a prática docente, potencializando perspectivas para o funcionamento da escrita em aulas de ciências, pelo ensino e pela pesquisa, em nossa contemporaneidade. 


\section{RELATIONS BETWEEN SCIENCE TEACHING AND WRITING:REFLECTIONS ON THE "ORIGINS" OF THEIR SEARCH IN BRAZIL}

ABSTRACT: This research aims to characterize understandings of Brazilian researchers of Scientific Education that were mediators of scientific knowledge development about the relations between the Science teaching and the writing. For this, it is socialized a sample of a state of the art research in that it was developed a historical- epistemological analysis of the researches about Writing, published in journals and scientific events in the area of science education, considering the Ludwik Fleck's epistemology theory and an understanding about language of the French Discourse Analysis. The interpretations made in this study allow us to understand when the publications were made, the trends of the scientific production throughout its history and the circulation of ideas among researchers and with other areas in order to respond to their problems research.

KEYwords: Science Teaching .Writing. Research. Circulation of ideas.

\section{RELACIONES ENTRE LA ENSEÑANZA DE LA CIENCIA NATURAL Y LA ESCRITURA: REFLEXIONES SOBRE LOS “ORÍGENES” DE SU INVESTIGACIÓN EN BRASIL}

ResUmen: Esta investigación tiene como objetivo caracterizar las comprensiones de investigadores brasileños de la Educación Científica que fueron mediadores en el desarrollo de los conocimientos científicos sobre las relaciones entre la enseñanza de las Ciencias naturales y la escritura. Para tanto, se socializó un recorte de una investigación del estado del arte, en que se hizo un análisis histórico-epistemológico de las investigaciones sobre la escritura, publicadas en periódicos y eventos científicos en la esfera de la Enseñanza de las Ciencias naturales, teniendo en cuenta los aportes teóricos de la epistemología de Ludwik Fleck y una comprensión del lenguaje del Análisis del Discurso francesa. Las interpretaciones permiten comprender cuando comenzaron las publicaciones, las tendencias de la producción científica a lo largo de su historia y la circulación de ideas entre investigadores de la Enseñanza de las Ciencias naturales con otras áreas a fin de responder a sus problemas de investigación.

Palabras Clave: Enseñanza de las Ciencias naturales. Escritura. Investigación. Circulación de ideas. 


\section{NOTAS}

1) Em pesquisa que originou um capítulo da tese de doutorado "Circulando sentidos, pela escrita, nas aulas de Ciências: Com interlocuções entre Fritz Müller, Charles Darwin e um coletivo de estudantes" (2012). Neste estudo, Tomio (2012) caracterizou as condições de produção para pesquisa sobre escrita no ensino de Ciências, considerando: a cronologia, a origem regional e institucional, as referências empregadas, os níveis de ensino, os sujeitos-escritores investigados, as modalidades de pesquisa, as áreas de conhecimentos envolvidas, os gêneros discursivos priorizados e os problemas investigados.

2) Compartilhamos da afirmação de Orlandi (2003) quando escreve que em nosso país, nas pesquisas sobre e com Análise de Discurso, mesmo com uma formulação própria, mantivemos, consistentemente, certos princípios sistematizados pelo francês Michel Pêcheux, que caracterizam uma filiação com a AD francesa, sobre as relações língua/ sujeito/ história ou, mais propriamente, sobre a relação língua/ ideologia, tendo o discurso como lugar de observação dessa relação.

3) "Além de constituir um coletivo de interlocução, a circulação intracoletiva de ideias tem como significado mais importante, na gênese e desenvolvimento de um conhecimento científico, possibilitar o reforço das criações intelectuais e, com isso, favorecer a extensão de um estilo de pensamento. [...] Não obstante, essa divulgação também promove a circulação intercoletiva de ideias, por meio da qual cientistas portadores de diferentes estilos de pensamento tomam conhecimento dos desenvolvimentos científicos de outras áreas. [...] Essa participação ou intercâmbio de ideias entre sujeitos de coletivos diferentes pode promover mudanças teóricas e metodológicas, gerando desde um deslocamento até a transformação total de um estilo de pensamento" (TOMIO, 2013, p. 269-70).

\section{REFERÊNCIAS}

ASEM, E. C. de A. D.; TRIVELATO, S. L. F. Argumentação científica de um filme infanto-juvenil e a escrita dos alunos: uma relação possível? In: ENCONTRO NACIONAL DE PESQUISA EM EDUCAÇÃO EM CIÊNCIAS, 7., 2009, Florianópolis. Anais... Florianópolis: ABRAPEC, 2009.

BRANDI, A. T. E.; GURGEL, C. M. do A. Alfabetização com/em Ciências: o caminho das mudanças na prática pedagógica de um professor alfabetizador. In: ENCONTRO NACIONAL DE PESQUISA EM EDUCAÇÃO EM CIÊNCIAS. 2, 1999, VALINHOS. Atas...Valinhos: ABRAPEC, 1999.

.; GURGEL, C. M. do A. A Alfabetização científica e o processo de ler e escrever em séries iniciais: emergências de um estudo de investigação-ação. Ciência e Educação, Bauru, v. 8, n.1, p. 113-125, 2002. 
CARLSEN, W. S. Language an science learning. In: ABELL, S. K.; LEDERMAN, N. G. (Org.). Handbook of Research on Science Education. London: Lawrence Erlbaum Associates, 2007. p. 57-74.

DELIZOICOV, D. Pesquisa em ensino de Ciências como Ciências Humanas aplicadas. Caderno Brasileiro de ensino de Física, São Paulo, v. 21, p. 145-175, ago. 2004.

DRIVER, R. et al. Construindo conhecimento científico na sala de aula. Química Nova na Escola, n. 9, p. 31-40, maio 1999.

FLECK, L. La génesis y el desarrollo de un hecho científico. Madrid: Alianza Editorial, 1986a.

. (1929). On the crisis of reality. In: COHEN, R. S.; SCHNELLE, T. (Ed.). Cognition and fact; materials on Ludwik Fleck. New York: Kluwar Academic Publishers, 1986b.

FREITAS, D. S.; PANIZ, C. M. Diário da Prática Pedagógica e a construção da reflexividade do profissional professor. In: ENCONTRO NACIONAL DE PESQUISA EM EDUCAÇÃO EM CIÊNCIAS. 5, 2005, BAURU. Atas... Bauru: ABRAPEC, 2005.

GALIAZZI, M. do C. et al. Narrar as histórias sobre o ser professor para constituir professores em formação. In: ENCONTRO NACIONAL DE PESQUISA EM EDUCAÇÃO EM CIÊNCIAS. 5, 2005, BAURU. Atas... Bauru: ABRAPEC, 2005.

GALILEI, Galileu. Diálogo sobre os dois máximos sistemas do mundo. 2. ed. São Paulo: Imprensa Oficial, 2004.

HALLIDAY, M. A. K.; MARTIN, J. R. Writing Science. London: Falmer Press, 1993.

HINGEL, F.; LIMA, M. da C. B.; XAVIER, J. C. Análise de redações de alunos de sexta e sétima série sobre um experimento. In: ENCONTRO NACIONAL DE PESQUISA EM EDUCAÇÃO EM CIÊNCIAS. 5, 2005, BAURU. Atas... Bauru: ABRAPEC, 2005.

LEMKE, J. L. Talking Science. Language, Learning and Values. New Jersey: Ablex Publishing Corporation, 1990.

LIMA, M. da C. B.; CARVALHO, A. M. P. de. Analisando o conhecimento físico através da linguagem. In: ENCONTRO NACIONAL DE PESQUISA EM EDUCAÇÃO EM CIÊNCIAS, 1., 1997, Águas de Lindóia. Atas... Águas de Lindóia: ABRAPEC, 1997.

$\therefore$ CARVALHO, A. M. P. de; GONÇALVES, M. E. R. A escrita e o desenho: instrumentos para a análise da evolução dos conhecimentos físicos. Caderno Catarinense de Ensino de Física, Florianópolis, v. 15, n. 3, p. 223-242, 1998.

MACHADO, A. H.; MOURA, A. L. Concepções sobre o papel da linguagem no processo de elaboração conceitual em Química. Química Nova na Escola, São Paulo, n. 2, 1995.

MACÍAS, A; MATURANO, C. I. Lenguaje, Intertextualidad y Bibliografía en los Trabajos de Investigadores en Educación en Ciencias. Enseñanza de las Ciencias, Barcelona, v. 18, n. 1, p. 71-77, 2000. 
MEGID NETO, J. O que se pesquisa sobre ensino de Ciências no nível fundamental: tendências de teses e dissertações defendidas entre 1972 e 1995. Revista Educação em Foco, Juiz de Fora, v. 6, n.1, p. 87-106, mar./ago. 2001.

MORAES, R.; GALIAZZI, M. do C. Análise Textual Discursiva: processo reconstrutivo de múltiplas faces. Ciência \& Educação, Bauru, v. 12, n. 1, p. 117-128, 2006.

MORTIMER, E. F. Construtivismo, mudança conceitual e ensino de Ciências: para onde vamos? Investigação em Ensino de Ciências, Porto Alegre, v. 1, n. 1, p. 20-39, 1996.

$\therefore$ CHAGAS, A. N.; ALVARENGA, V. T. Linguagem científica versus Linguagem comum nas respostas escritas de vestibulandos. In: ENCONTRO NACIONAL DE PESQUISA EM EDUCAÇÃO EM CIÊNCIAS, 1, 1997, Águas de Lindóia. Atas... Águas de Lindóia: ABRAPEC, 1997.

; CHAGAS, A. N.; ALVARENGA, V. T. Linguagem científica versus linguagem comum nas respostas escritas de vestibulandos. Investigações em Ensino de Ciências, Porto Alegre, v. 3, n. 1, p. 7-19, 1998.

..; SCOTT, P. Atividade discursiva nas salas de aula de Ciências: uma ferramenta Sociocultural para analisar e planejar o ensino. Investigações em Ensino de Ciências, Porto Alegre, v. 7, n. 3, p. 283-306, 2002.

OLIVEIRA, J. R. S. de; BATISTA, A. A.; QUEIROZ, S. L. Modelo de argumentação como ferramenta para análise da qualidade da escrita científica de alunos de graduação em Química. In: ENCONTRO NACIONAL DE PESQUISA EM EDUCAÇÃO EM CIÊNCIAS, 7., 2009, Florianópolis. Atas... Florianópolis: ABRAPEC, 2009.

ORLANDI, E. P. Silêncios: presença e ausência. Com Ciência, Campinas, n. 101, 10 set. 2008. Análise do Discurso: princípios e procedimentos. 8. ed. Campinas: Pontes, 2009.

A Análise de Discurso em suas diferentes tradições intelectuais: o Brasil. In: SEMINÁRIO DE ESTUDOS EM ANÁLISE DE DISCURSO, 1, 2003, Porto Alegre. Anais... Porto Alegre: UFRGS, 2003. Disponível em: <http://www.ufrgs.br/analisedodiscurso/ anaisdosead/1SEAD/Conferencias/EniOrlandi.pdf>. Acesso em: 07 set. 2016.

PEREIRA, M. M.; SOARES, V.; ANDRADE, V. A. de. Escrita como ferramenta indicativa das possíveis contribuições de uma atividade investigativa sobre a temperatura para a aprendizagem. In: ENCONTRO NACIONAL DE PESQUISA EM EDUCAÇÃO EM CIÊNCIAS, 8., 2011, Campinas. Anais... Campinas: ABRAPEC, 2011.

PINHÃO, F.; MARTINS, I. A Análise de Discurso e a pesquisa em ensino de ciências no Brasil: um levantamento da produção em periódicos entre e 1998 e 2008. In: ENCONTRO NACIONAL DE PESQUISA EM EDUCAÇÃO EM CIÊNCIAS, 7., 2009, Florianópolis. Anais... Florianópolis: ABRAPEC, 2009.

RIVARD, L. P. A review of writing to learn in science: implications for practice and research. Journal of Research in Science Teaching, n. 31, p. 969-983, 1994. 
SCOTT, P.H. Teacher talk and meaning making in science classrooms: A Vygotskian analysis and review. Studies in Science Education, n. 32, p. 45-80, 1998.

SOARES, A. G.; COUTINHO, F. A. Leitura, discussão e produção de textos como recurso didático para o ensino de Biologia. In: ENCONTRO NACIONAL DE PESQUISA EM EDUCAÇÃO EM CIÊNCIAS. 6, 2007, FLORIANÓPOLIS. Anais... Florianópolis: ABRAPEC, 2007.

TOMIO, D. Circulando sentidos, pela escrita, nas aulas de ciências: com interlocuções entre Fritz Müller, Charles Darwin e um coletivo de estudantes. 2012. 368 f. Tese (Doutorado) - Curso de Pós-Graduação em Educação Científica e Tecnológica, Universidade Federal de Santa Catarina, Florianópolis, 2012.

Dear Mr. Charles Darwin... Dear Mr. Fritz Müller: da correspondência entre o evolucionista e o naturalista indícios para caracterizar a escrita na ciência e no ensino de ciências. Investigações em Ensino de Ciências, Porto Alegre, v. 18, n. 2, p. 263-281, 2013.

VALLE, M. G. do. A argumentação na produção escrita de professores de ciências e o ensino de genética. In: ENCONTRO NACIONAL DE PESQUISA EM EDUCAÇÃO EM CIÊNCIAS, 7., 2009, Florianópolis. Anais... Florianópolis: ABRAPEC, 2009.

VALLE, M. G. do; MOTOKANE, M. T. A argumentação na produção escrita de professores de ciências e o ensino da genética. In: ENCONTRO NACIONAL DE PESQUISA EM EDUCAÇÃO EM CIÊNCIAS, 7., 2009, Florianópolis. Anais... Florianópolis: ABRAPEC, 2009.

YORE, L. D.; BISANZ, G. L.; HAND, B. M. Examining the literacy component of science literacy: 25 years of language arts and science research. International Journal of Science Education, v. 25, n. 6, p. 689-725, 2003.

DANIELA TOMIO: Doutora em Educação Científica e Tecnológica (PPGECT/UFSC). Docente pesquisadora na Universidade Regional de Blumenau, nos cursos de Pós-Graduação Mestrado em Educação e Mestrado em Ensino de Ciências Naturais e Matemática. Editora do periódico científico FURB - Revista Dynamis. Trabalha na formação inicial e continuada de professores da Educação básica e do Ensino superior. Coordenadora do Sub-projeto PIBID Biologia. Atua e pesquisa principalmente nas seguintes áreas: Contextos de atuação e formação docente na Educação Básica; Ensino de Ciências, Educação Ambiental e Metodologia da Pesquisa.

E-mail: danitomiobr@smail.com 
